\title{
Successful Use of BRAF/MEK Inhibitors as a Neoadjuvant Approach in the Definitive Treatment of Papillary Craniopharyngioma
}

Karam Khaddour, MD; Michael R. Chicoine, MD²; Jiayi Huang, MD³; Sonika Dahiya, MD; and George Ansstas, MD¹

\begin{abstract}
Craniopharyngiomas are rare tumors that arise in the suprasellar region of the brain and are known for their aggressive nature despite their WHO grade I. This is due to the complex neuroanatomy of the sellar/suprasellar region and their proximity to the optic nerve apparatus, hypothalamic-pituitary tract, and other critical neuroanatomical structures. Definitive treatment is based on a multidisciplinary approach and often involves a combination of surgical, radiation, and medical therapy. However, there is high morbidity associated with surgery and RT due to the complex neuroanatomy of this region. Recently, BRAF ${ }^{\mathrm{V} 600 \mathrm{E}}$ somatic mutation has been identified in most papillary craniopharyngiomas. This discovery has led to the novel use of RAF pathway inhibitors to treat these tumors. We report the successful use of dabrafenib (BRAF inhibitor) and trametinib (mitogen-activated protein kinase kinase inhibitor) in the neoadjuvant setting followed by definitive stereotactic radiosurgery. We propose an algorithm based on available literature on the integration of targeted therapy in the management of papillary craniopharyngiomas. Our observations, together with prior case reports, advocate the incorporation of targeted therapy for unresectable craniopharyngiomas and reinforce that treatment with dualtargeted therapy is safe and effective.
\end{abstract}

J Natl Compr Canc Netw 2020;18(12):1590-1595 doi: $10.6004 /$ jnccn.2020.7624

${ }^{1}$ Division of Medical Oncology, Department of Medicine, ${ }^{2}$ Department of Neurologic Surgery, ${ }^{3}$ Department of Radiation Oncology, and ${ }^{4}$ Division of Neuropathology, Department of Pathology and Immunology, Washington University School of Medicine, St. Louis, Missouri.
The identification of a somatic point mutation in $B R A F$ in many tumor types, including melanoma and NSCLC, led to the development of therapies that target the RAF kinase pathway and have shown acceptable efficacy and safety. ${ }^{1,2}$ Interestingly, the $B R A F^{\mathrm{V} 600 \mathrm{E}}$ mutation has also been identified in primary intracranial tumors, albeit with an overall lower frequency, with the highest incidence reported in ganglioglioma, pleomorphic xanthoastrocytoma, and papillary craniopharyngioma (Figure 1). ${ }^{3}$ However, single and dual-targeted therapy has shown variable efficacy and nonsustained responses among subtypes of primary intracranial tumors, with most of the subtypes showing progressive disease during treatment. ${ }^{4-6}$ Interestingly, papillary craniopharyngiomas, which are associated with a high incidence of $B R A F^{\mathrm{V} 600 \mathrm{E}}(\sim 95 \%$ of cases), appear to respond well to single and dualtargeted molecular therapy, with most of these tumors showing complete response or partial sustained response (Table 1). ${ }^{7}$ This report emphasizes the importance of consideration of clinical trials evaluating the efficacy and safety of targeted molecular therapy and the implementation of the neoadjuvant use of targeted therapy in a multidisciplinary approach for the management of unresectable $B R A F^{\mathrm{V} 600 \mathrm{E}}$ mutant papillary craniopharyngiomas and tumors that are considered ineligible for radiation therapy (RT).

\section{Case Report}

A 39-year-old previously healthy man presented to Washington University School of Medicine with a 4-month history of headache and peripheral visual disturbance (bitemporal hemianopsia) (Figure 2). Initial brain MRI demonstrated a large enhancing suprasellar mass abutting the optic chiasm, suspicious for craniopharyngioma (Figure 3A). He underwent endoscopic endonasal transsphenoidal near-complete resection of the mass. Small residual fragments of the tumor were left behind along the optic chiasm and pituitary stalk to avoid the morbidity associated 


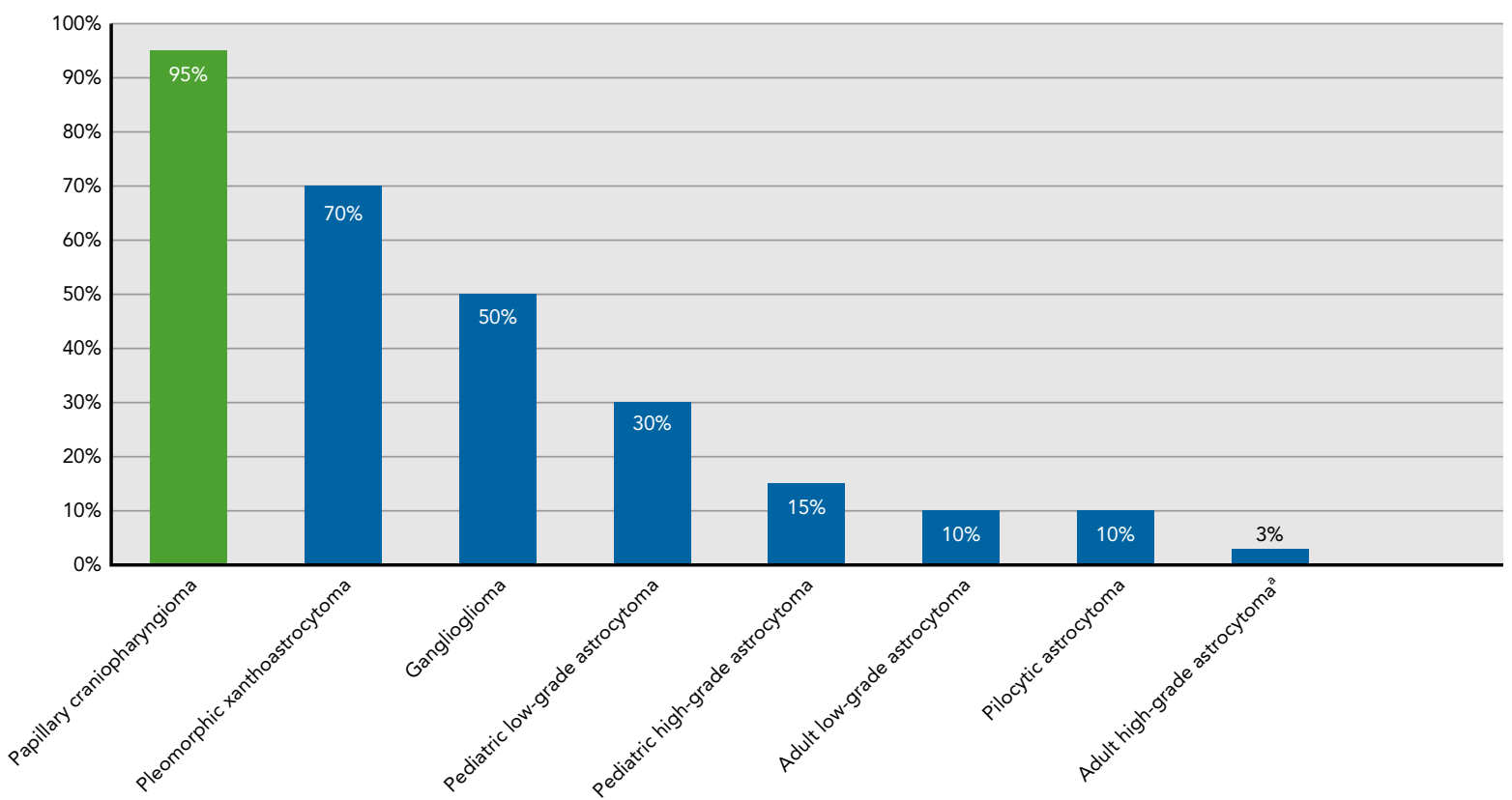

Figure 1. Frequency of $B R A F^{V 600 E}$ mutation in primary intracranial tumors.

aEpithelioid subtype of glioblastoma multiforme is associated with higher frequency ( $50 \%)$.

with further manipulation. Histologic examination of the tumor showed mature squamous epithelium around broad fibrovascular cores without keratinization or identifiable wet keratin, altogether consistent with a papillary craniopharyngioma, WHO grade I (Figure 4A). The result of immunohistochemistry for mutant BRAF (p.V600E) was positive (Figure 4B), which was further corroborated by next-generation sequencing (NGS).

At his follow-up visit 5 months after the surgery, the patient continued to have persistent headaches and peripheral vision loss, but they were milder than the initial symptoms reported before surgery. Brain MRI revealed interval development of a new, partially cystic structure in the region of the suprasellar cistern with peripheral and nodular enhancement and diffusion restriction and mass effect concerning for disease progression (Figure 3B). The optic chiasm and optic tracts were displaced and splayed outward, with the mass abutting bilateral anterior cerebral arteries. Further surgical resection or radiosurgery would pose significant risk of morbidity due to adherence of the recurrent tumor to the optic apparatus. Given the presence of somatic $B R A F^{\mathrm{V} 600 \mathrm{E}}$ mutation in the tumor, the patient elected to be treated with neoadjuvant combination BRAF/MEK inhibition with oral dabrafenib (150 mg twice daily) and trametinib ( $2 \mathrm{mg}$ once daily) in an attempt to decrease the tumor size before treatment with definitive surgery or radiosurgery. MRI of the brain 6 weeks after initiation of dual-targeted therapy showed that both cystic and nodular enhancement of the tumor improved, with almost $50 \%$ volume reduction. The treatment course with trametinib and dabrafenib continued for a total of 9 months. The patient experienced mild pyrexia (grade I fever according to CTCAE version 5.0.), which required treatment interruption for 4 days before later resuming the previous dosage.

After conclusion of 9 months of dual-targeted therapy, brain MRI showed sustained radiologic response ( $>70 \%$ reduction in size), with a small, stable residual tumor (Figure 3C). Neurosurgery and radiation oncology evaluations were performed, and the patient was deemed a candidate for radiosurgery. Both single-fraction radiosurgery and fractionated radiosurgery were deemed feasible, but we elected to proceed with fractionated radiosurgery because it was thought to present a lower risk of injury to the optic nerve, given its relative proximity. The patient underwent fractionated Gamma Knife radiosurgery (Icon system; Elekta) over 5 daily fractions to a total of $25 \mathrm{~Gy}$ prescribed to the $50 \%$ isodose line. Tumor volume was $176 \mathrm{~mm}^{3}$, and the maximum dose to the optic apparatus was $16 \mathrm{~Gy}$ (well below the typical dosimetric threshold of $25 \mathrm{~Gy}$ ). After radiosurgery, the patient's symptoms completely resolved, and repeat brain MRI (18 months after radiosurgery) revealed no evidence of disease recurrence (Figure 3D). The patient was subsequently followed with clinical evaluation and brain 


\begin{tabular}{|c|c|c|c|c|c|c|c|c|}
\hline Study & Age, Sex & $\begin{array}{l}\text { Method of BRAF } \\
\text { Mutation } \\
\text { Detection }\end{array}$ & $\begin{array}{l}\text { Sequence of } \\
\text { Therapy }\end{array}$ & $\begin{array}{l}\text { Regimen (Dose, } \\
\text { Frequency) }\end{array}$ & $\begin{array}{l}\text { Tumor } \\
\text { Volume } \\
\text { Reduction } \\
\text { (\%) }\end{array}$ & $\begin{array}{l}\text { Radiologic } \\
\text { Response }\end{array}$ & Final Outcome & $\begin{array}{l}\text { Complications } \\
\text { During Treatment } \\
\text { With Targeted } \\
\text { Therapy }\end{array}$ \\
\hline $\begin{array}{l}\text { Aylwin } \\
\text { et al, } \\
2016^{14}\end{array}$ & $27 y$, female & Pyrosequencing & $\begin{array}{l}\text { Multiple surgeries } \\
\text { (3) }+\mathrm{RT} \rightarrow \mathrm{TG}\end{array}$ & $\begin{array}{l}\text { Vemurafenib, } \\
960 \text { mg bid }\end{array}$ & NA & $\begin{array}{l}\text { CR } \\
\text { followed } \\
\text { by PD } 7 \mathrm{mo} \\
\text { later }\end{array}$ & $\begin{array}{l}\text { PD } 7 \text { mo after } \\
\text { vemurafenib }\end{array}$ & $\begin{array}{l}\text { CSF leak, } \\
\text { pneumocephalus, } \\
\text { meningitis (due to } \\
\text { tumor shrinkage) }\end{array}$ \\
\hline $\begin{array}{l}\text { Himes et al, } \\
2019^{15}\end{array}$ & $47 \mathrm{y}$, male & NA & $\begin{array}{l}\text { Surgery (1) } \rightarrow \\
\text { RT } \rightarrow \text { TG }\end{array}$ & $\begin{array}{l}\text { Dabrafenib, } \\
150 \mathrm{mg} \mathrm{bid}^{\mathrm{b}}\end{array}$ & $>50$ & PR & SD at $2 y$ & Joint pain \\
\hline $\begin{array}{l}\text { Rao et al, } \\
2019^{16}\end{array}$ & $35 \mathrm{y}$, male & NGS & $\begin{array}{l}\text { Surgery }(1) \rightarrow \\
\text { TG }\end{array}$ & $\begin{array}{l}\text { Dabrafenib, } \\
150 \mathrm{mg} \text { bid }\end{array}$ & NA & $\mathrm{CR}$ & $\mathrm{CR}$ at $2 \mathrm{y}$ & None \\
\hline $\begin{array}{l}\text { Brastianos } \\
\text { et al, } \\
2015^{17}\end{array}$ & $39 \mathrm{y}$, male & IHC, blood, WES & $\begin{array}{l}\text { Multiple surgeries } \\
\text { (3) } \rightarrow \mathrm{TG} \rightarrow \mathrm{RT}\end{array}$ & $\begin{array}{l}\text { Dabrafenib, } \\
150 \text { mg bid; } \\
\text { trametinib, } 2 \text { mg bid }\end{array}$ & $85 \%$ & PR & $\begin{array}{l}\text { Free of } \\
\text { symptoms at } 7 \\
\text { mo after RT }\end{array}$ & $1 \mathrm{~d}$ of pyrexia \\
\hline $\begin{array}{l}\text { Roque \& } \\
\text { Odia, } \\
2017^{18}\end{array}$ & $47 y$, female & $\mathrm{IHC}, \mathrm{NGS}$ & $\begin{array}{l}\text { Surgery }(1) \rightarrow \\
\text { RT } \rightarrow \text { TG }\end{array}$ & $\begin{array}{l}\text { Dabrafenib, } 150 \\
\text { mg bid; trametinib, } \\
2 \text { mg qd }\end{array}$ & $\sim 80 \%$ & PR & $\begin{array}{l}\text { Continued } \\
\text { clinical and } \\
\text { radiologic } \\
\text { response after } \\
7 \text { mo }\end{array}$ & $\begin{array}{l}\text { Intermittent } \\
\text { pyrexia }\end{array}$ \\
\hline $\begin{array}{l}\text { Rostami } \\
\text { et al, } \\
2017^{19}\end{array}$ & $65 \mathrm{y}$, male & $\begin{array}{l}\mathrm{IHC} \text {, } \\
\text { pyrosequencing }\end{array}$ & $\begin{array}{l}\text { Surgery }(1) \rightarrow \\
\text { TG } \rightarrow \text { proton } \\
\text { therapy }\end{array}$ & $\begin{array}{l}\text { Dabrafenib, } \\
150 \text { mg bid; } \\
\text { trametinib, } 2 \text { mg qd }\end{array}$ & $91 \%$ & $C R$ & $\begin{array}{l}\text { Radiologic } \\
\text { response after } \\
15 \text { wk of } \\
\text { treatment }\end{array}$ & $\begin{array}{l}\text { Pyrexia leading to } \\
\text { medication } \\
\text { discontinuation }\end{array}$ \\
\hline $\begin{array}{l}\text { Bernstein } \\
\text { et al, } \\
2019^{20}\end{array}$ & $60 \mathrm{y}$, male & NGS & $\begin{array}{l}\text { Surgery (4) } \rightarrow \\
\text { RT } \rightarrow \text { TG }\end{array}$ & $\begin{array}{l}\text { Dabrafenib, } \\
150 \text { mg bid; } \\
\text { trametinib, } 2 \text { mg qd }\end{array}$ & NA & $C R$ & $\mathrm{CR}$ at $28 \mathrm{mo}$ & $\begin{array}{l}\text { Widespread } \\
\text { verrucal keratoses }\end{array}$ \\
\hline
\end{tabular}

Abbreviations: CR, complete response; CSF, cerebrospinal fluid; NA, not available; NGS, next-generation sequencing; IHC, immunohistochemistry; PD, progressive disease; PR, partial response; RT, radiotherapy; SD, stable disease; TG, targeted therapy; WES, whole-exome sequencing.

aTreatment was interrupted.

bDose was changed during treatment course due to adverse effects.

MRI every 6 months. At the time of this report, he has been in remission for 2 years.

\section{Discussion}

Despite the benign histologic nature of craniopharyngiomas, their location and proximity to critical structures in the brain account for aggressive clinical behavior. Definitive treatment has been focused on a conservative surgical approach with or without RT to avoid complications related to manipulation of structures surrounding the tumor, such as the optic apparatus and the hypothalamic-pituitary system. Although craniopharyngiomas are associated with excellent overall survival prognosis (10-year survival rate of $90 \%$ ), recurrence and complications from surgery and RT can lead to substantially impaired quality of life, including visual defects, epilepsy, hypopituitarism, diabetes insipidus, hypothalamic obesity, and other neurologic deficits. ${ }^{8}$ For example, in a series of 123 patients with craniopharyngioma who were treated with a multimodality approach including surgery and RT with a median follow-up of 8.9 years, there were incidence rates of $11 \%$ cardiovascular events, $76 \%$ pituitary hormone deficiencies, $16 \%$ seizures, $45 \%$ diabetes insipidus, and $27 \%$ visual disturbance. ${ }^{9}$ The difficulty in treating recurrent disease and the desire to avoid comorbidities associated with available therapy have led to the study of several systemic therapies in pediatric and adult tumors, with mixed outcomes. ${ }^{10-12}$ Identification of clonal somatic gene mutation in $B R A F^{\mathrm{V} 600 \mathrm{E}}$ in papillary craniopharyngioma has advanced the molecular approach to distinguish this tumor from the other subtype (adamantinomatous craniopharyngiomas). The frequency of $B R A F^{\mathrm{V} 600 \mathrm{E}}$ mutation was found to be high in papillary



Figure 2. Timeline of the clinical course of the patient's craniopharyngioma. 


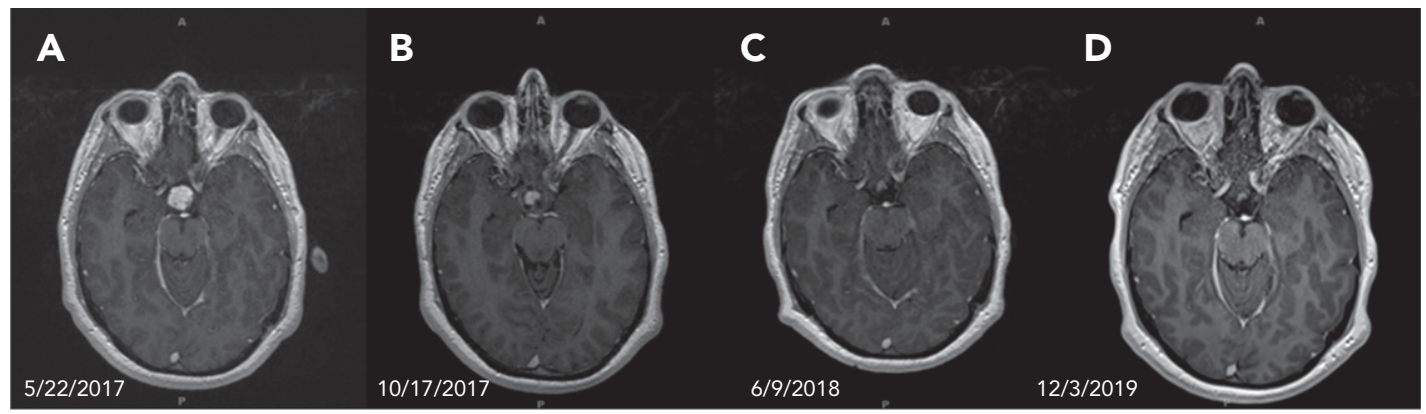

Figure 3. MRI of the brain. (A) Postcontrast T1-weighted image shows large homogeneously enhancing mass measuring $1.9 \times 1.7 \times 2.1 \mathrm{~cm}$. (B) Recurrence of a new cystic structure in the region of the suprasellar cistern that measures approximately $1.8 \times 1.5 \times 2.0 \mathrm{~cm}$ with peripheral enhancement and nodular enhancement along the inferior-most aspect of the lesion. The optic chiasm and optic tracts are displaced and splayed outward with the mass abutting bilateral anterior cerebral arteries. (C) A faint focus of enhancement can be seen in the suprasellar cistern, which measures $0.6 \times 0.6 \mathrm{~cm}$. (D) An ill-defined enhancement anterior to the pituitary stalk now measuring $0.5 \times 0.3 \mathrm{~cm}$ abutting the optic chiasm within the vicinity of the hypothalamus.

craniopharyngioma using exome sequencing in the study by Brastianos et $\mathrm{al}^{7}$ that identified this mutation in 36 of 39 tumor samples (95\% of cases). Although there are no clear recommendations regarding the test with the best sensitivity and specificity to detect somatic $B R A F$ mutations in papillary craniopharyngioma, we recommend an approach using DNA-based testing (such as PCR or NGS) and antibody-based testing (immunohistochemistry to detect mutant $B R A F$ protein), given the increased sensitivity and specificity of combined testing. ${ }^{7,13}$

Several case reports have demonstrated the robust clinical response of $B R A F^{\mathrm{V} 600 \mathrm{E}}$-positive papillary craniopharyngioma when treated with a single-agent BRAF inhibitor $^{14-16}$ or with dual-targeted therapies using BRAF/MEK inhibitors. ${ }^{17-20}$ The rationale of using combined BRAF/MEK inhibitors is based on the additive effect of MEK inhibitors, which can augment blockade of the downstream pathway of mitogen-activated protein kinase. This was supported in phase III clinical trials in metastatic melanoma that demonstrated improved progression-free and overall survival in patients treated with combined BRAF/MEK inhibitors compared with those who received a single-agent BRAF inhibitor. ${ }^{21}$ Moreover, use of combined BRAF/MEK inhibitors is associated with a delay in the development of resistance and lower cutaneous toxicities, albeit with an increased risk of pyrexia and chills, which can lead to treatment discontinuation. ${ }^{21}$ Most of the literature on treatment of craniopharyngiomas with targeted therapy has reported the use of RAF pathway inhibitors in the setting of recurrent disease after several surgical and RT approaches failed to control tumor growth, with most of these cases showing partial responses based on Response Assessment in Neuro-Oncology (RANO) criteria. ${ }^{22}$ Notably, progressive disease was observed in one case report after treatment with vemurafenib alone. ${ }^{12}$ Therefore, given the previous observations of partial responses and possible progressive disease with use of a BRAF inhibitor alone, we elected to pursue combined BRAF/MEK inhibition as a neoadjuvant therapy followed by definitive radiosurgery. We believed such an approach offered a few

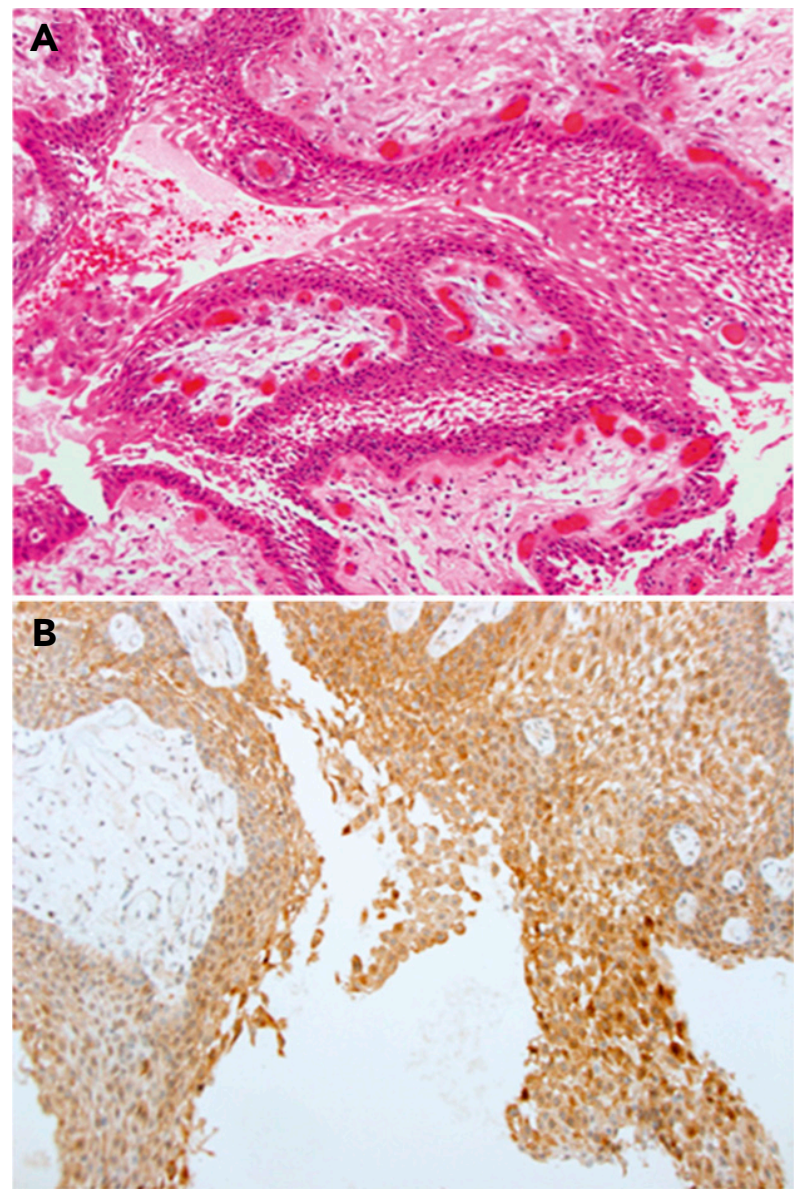

Figure 4. (A) Histologic examination shows mature squamous epithelium without keratinization around broad fibrovascular cores (hematoxylineosin, original magnification $\times 20$ ). (B) Diffuse and strong immunoreactivity (VE1 antibody) for mutant BRAF protein (V600E) in the neoplastic squamous epithelial cells (original magnification, $\times 20$ ). 


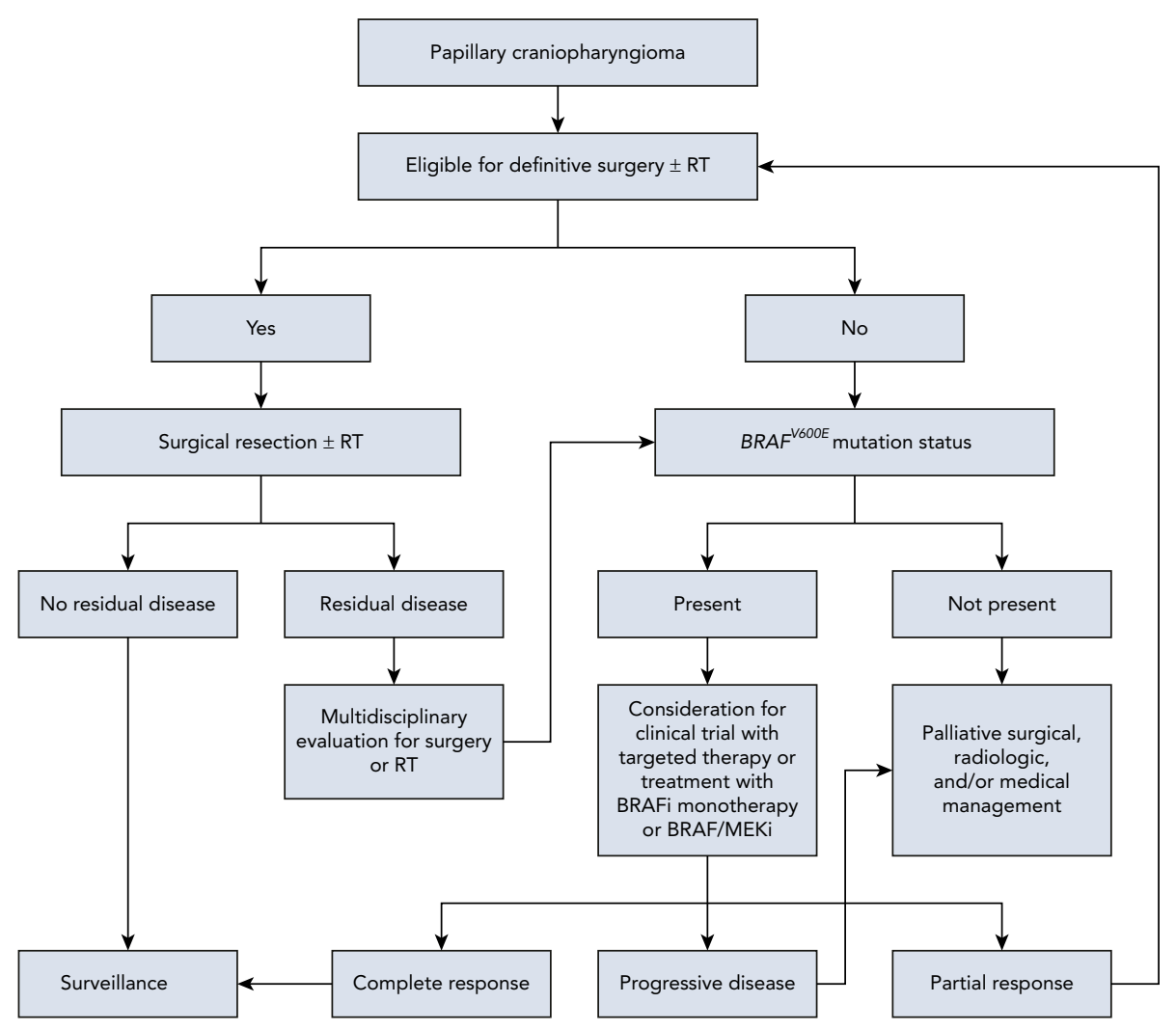

Figure 5. Algorithm outlining management of papillary craniopharyngioma. Decision to integrate targeted therapy at initial diagnosis is advised only in the context of a clinical trial. Various factors can alter the sequence of the suggested treatment algorithm, such as institution protocols, availability of targeted therapy, physician familiarity with targeted therapy, and cost.

Abbreviations: BRAFi, BRAF inhibitor; MEKi, mitogen-activated protein kinase inhibitor; RT, radiotherapy.

advantages: reducing tumor volume to facilitate definitive and noninvasive radiosurgery, avoiding morbidities of additional surgeries, and eliminating the uncertainty of lifelong BRAF inhibition or the risk of drug resistance.

Based on our observation, combined with those of previous case reports, we propose an algorithm for the management of papillary craniopharyngioma (Figure 5). A clinical trial is ongoing to evaluate the safety and efficacy of dual-targeted therapy in papillary craniopharyngioma (ClinicalTrials.gov identifier: NCT03224767), which will provide prospective validation of this approach.

\section{Conclusions}

This report describes an adult patient with $B R A F^{V 600 E}$-positive recurrent papillary craniopharyngioma successfully treated with combined dabrafenib and trametinib followed by definitive radiosurgery. The patient had a significant clinical and radiographic response consistent with prior results using dual BRAF/MEK inhibitors in papillary craniopharyngioma. Furthermore, our observation and the previously reported literature suggest the following: (1) screening for the presence of BRAF point mutations in papillary variants of craniopharyngiomas should be part of the initial diagnostic workup; (2) treatment with targeted therapy in BRAF-mutant papillary craniopharyngioma is safe and effective, particularly in patients deemed to be poor candidates for definitive surgery or RT; and (3) integration of targeted therapies in a multimodality approach could mitigate comorbidities associated with surgery and RT. Although this case report provides proof of concept, validation in larger patient cohorts and clinical trials would be essential.

Submitted June 4, 2020; accepted for publication July 20, 2020.

Disclosures: Dr. Chicoine has disclosed that he has received grant/research support from IMRIS Inc.; the Head for the Cure Foundation; and Mrs. Carol Rossfeld and the Alex and Alice Aboussie Charitable Foundation. Dr. Huang has disclosed that he has received grant/research support from Pfizer. The remaining authors have disclosed that they have not received any financial consideration from any person or organization to support the preparation, analysis, results, or discussion of this article.

Disclaimer: The REDCap database is supported by Clinical and Translational Science Award (grant UL1 TR000448), the Siteman Cancer Center, and NCI Cancer Center (grant P30 CA091842).

Correspondence: George Ansstas, MD, Division of Medical Oncology, Department of Medicine, Washington University School of Medicine, 660 South Euclid Avenue, St. Louis, MO 63110. Email: gansstas@wustl.edu 


\section{References}

1. Long GV, Flaherty KT, Stroyakovskiy D, et al. Dabrafenib plus trametinib versus dabrafenib monotherapy in patients with metastatic BRAF V600E/ K-mutant melanoma: long-term survival and safety analysis of a phase 3 study. Ann Oncol 2017;28:1631-1639.

2. Hyman DM, Puzanov I, Subbiah V, et al. Vemurafenib in multiple nonmelanoma cancers with BRAF V600 mutations. N Engl J Med 2015;373:726-736.

3. Schreck KC, Grossman SA, Pratilas CA. BRAF mutations and the utility of RAF and MEK inhibitors in primary brain tumors. Cancers (Basel) 2019;11:1262.

4. Johanns TM, Ferguson CJ, Grierson PM, et al. Rapid clinical and radiographic response with combined dabrafenib and trametinib in adults with BRAFmutated high-grade glioma. J Natl Compr Canc Netw 2018;16:4-10.

5. Johanns TM, Ansstas G, Dahiya S. BRAF-targeted therapy in the treatment of BRAF-mutant high-grade gliomas in adults. J Natl Compr Canc Netw 2018; $16: 451-454$

6. Smith-Cohn M, Davidson $\mathrm{C}$, Colman $\mathrm{H}$, et al. Challenges of targeting $B R A F$ V600E mutations in adult primary brain tumor patients: a report of two cases. CNS Oncol 2019;8:CNS48.

7. Brastianos PK, Taylor-Weiner A, Manley PE, et al. Exome sequencing identifies BRAF mutations in papillary craniopharyngiomas. Nat Genet 2014;46:161-165

8. Karavitaki N, Brufani C, Warner JT, et al. Craniopharyngiomas in children and adults: systematic analysis of 121 cases with long-term follow-up. Clin Endocrinol (Oxf) 2005;62:397-409.

9. Lo AC, Howard AF, Nichol A, et al. Long-term outcomes and complications in patients with craniopharyngioma: the British Columbia Cancer Agency experience. Int J Radiat Oncol Biol Phys 2014;88:1011-1018.

10. Hargrave DR. Does chemotherapy have a role in the management of craniopharyngioma? J Pediatr Endocrinol Metab 2006;19(Suppl 1):407-412.

11. Kilday JP, Caldarelli M, Massimi L, et al. Intracystic interferon-alpha in pediatric craniopharyngioma patients: an international multicenter assessment on behalf of SIOPE and ISPN. Neuro Oncol 2017;19:1398-1407.

12. Grob S, Mirsky DM, Donson AM, et al. Targeting IL-6 is a potential treatment for primary cystic craniopharyngioma. Front Oncol 2019;9:791.
13. Cheng L, Lopez-Beltran A, Massari $F$, et al. Molecular testing for BRAF mutations to inform melanoma treatment decisions: a move toward precision medicine. Mod Pathol 2018;31:24-38

14. Aylwin SJ, Bodi I, Beaney R. Pronounced response of papillary craniopharyngioma to treatment with vemurafenib, a BRAF inhibitor. Pituitary 2016;19:544-546.

15. Himes BT, Ruff MW, Van Gompel JJ, et al. Recurrent papillary craniopharyngioma with BRAF V600E mutation treated with dabrafenib: case report. J Neurosurg 2019;130:1299-1303.

16. Rao M, Bhattacharjee M, Shepard S, et al. Newly diagnosed papillary craniopharyngioma with BRAF V600E mutation treated with single-agent selective BRAF inhibitor dabrafenib: a case report. Oncotarget 2019;10: 6038-6042.

17. Brastianos PK, Shankar GM, Gill CM, et al. Dramatic response of BRAF V600E mutant papillary craniopharyngioma to targeted therapy. J Natl Cancer Inst 2015;108:djv310.

18. Roque A, Odia Y. BRAF-V600E mutant papillary craniopharyngioma dramatically responds to combination BRAF and MEK inhibitors. CNS Oncol 2017;6:95-99.

19. Rostami E, Witt Nyström P, Libard S, et al. Recurrent papillary craniopharyngioma with BRAFV600E mutation treated with neoadjuvanttargeted therapy. Acta Neurochir (Wien) 2017;159:2217-2221.

20. Bernstein A, Mrowczynski OD, Greene A, et al. Dual BRAF/MEK therapy in BRAF V600E-mutated primary brain tumors: a case series showing dramatic clinical and radiographic responses and a reduction in cutaneous toxicity [published online November 1, 2019]. J Neurosurg, doi: 10.3171/ 2019.8.JNS19643

21. Long GV, Stroyakovskiy D, Gogas H, et al. Dabrafenib and trametinib versus dabrafenib and placebo for Val600 BRAF-mutant melanoma: a multicentre double-blind, phase 3 randomised controlled trial. Lancet 2015;386:444-451.

22. Wen PY, Macdonald DR, Reardon DA, et al. Updated response assessment criteria for high-grade gliomas: response assessment in neurooncology working group. J Clin Oncol 2010;28:1963-1972.

\section{NCCN $\begin{aligned} & \text { National Comprehensive } \\ & \text { Cancer Network }\end{aligned}$}

\section{NCCN 2021 VIRTUAL CONGRESS:

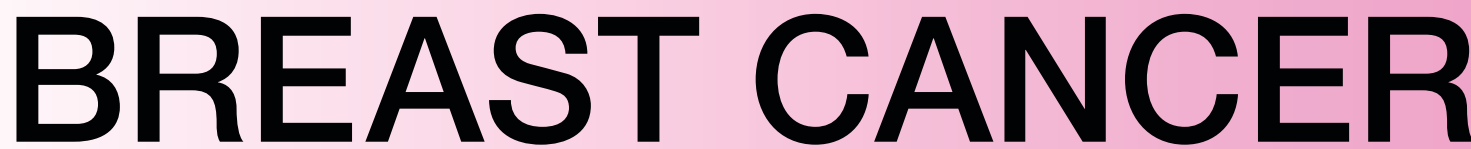

with Updates from the 2020 San Antonio Breast Cancer Symposium

In partnership with by Robert H. Lurie Comprehensive Cancer Center of Northwestern University

Friday, February 12, 2021 | 10:30 AM - 5:15 PM EST

NCCN.org/events 